\title{
Structural, optical and morphological study of tungsten selenide thin films
}

\author{
S. Arulmozhi Packiaseeli ${ }^{1}$, V. Rajendran ${ }^{2}$ and R. Vijayalakshmi ${ }^{3}$ \\ ${ }^{1}$ P.G. \& Research Department of Physics, Fatima College, Madurai, India \\ ${ }^{2}$ Department of Physics, Vivekananda College, Madurai, India \\ ${ }^{3}$ P.G. \& Research Department of Physics, Thiagarajar. College, Madurai, India \\ arulmozhipackiaseeli@gmail.com,ramyarv@rediffmail.com
}

\begin{abstract}
Tungsten selenide $\left(\mathrm{WSe}_{2}\right)$ film was successfully deposited on FTO substrate by brush plating technique. The film was uniform and well adherent to the substrate and annealed to $300{ }^{\circ} \mathrm{C}$ and $500{ }^{\circ} \mathrm{C}$. As the annealing temperature was increased the orientation of the crystallites was more randomized than in the as-prepared film. The structural and optical properties of the film were investigated by XRD, SEM, EDAX, UV-Visible and PL. The XRD pattern indicates that this film was crystallized in the hexagonal structure.
\end{abstract}

Keywords: WSe thin film, morphology.

Received: 5 February 2016

Revised: 3 May 2016

\section{Introduction}

Metal Chalcogenide thin films such as tungsten selenide films are promising semiconducting materials suitable for solar cells. Tungsten selenide thin films have band gaps of $2.16 \mathrm{eV} \leq E_{g} \leq 2.65 \mathrm{eV}$ and reasonable overlap with the solar spectrum [1]. Tungsten selenide thin film has direct band gap and is transparent over a wide range of the visible spectrum. It can be seen that the photoelectronic and other properties of class II-VI compound thin films are highly optically sensitive, which in turn can severely influence device performance. More progress has been achieved in the fabrication of light emitting diodes, dielectric mirrors and other optically sensitive devices [2].

\section{Experimental procedure}

Precursor solution was prepared by magnetically stirring $1 \mathrm{~g}$ of tungsten trioxide $\left(\mathrm{WO}_{3}\right)$ and $0.05 \mathrm{~g}$ of selenium dioxide $\left(\mathrm{SeO}_{2}\right)$ with $5 \mathrm{ml}$ of distilled water until the powder was thoroughly mixed to form a homogenous solution. The tungsten selenide thin films were prepared by Brush Plating technique on the FTO (Fluorine doped Tin Oxide) substrate. The as-deposited films were annealed at $300{ }^{\circ} \mathrm{C}$ and $500{ }^{\circ} \mathrm{C}$ for about 1 hour. The structural optical and morphological properties of the as-deposited and annealed tungsten selenide thin films were studied.

\section{Results and discussion}

\subsection{XRD Analysis}

Figure 1(a) shows the XRD pattern of the as-deposited tungsten selenide film on the FTO (Fluorine doped Tin Oxide) substrate. The as-deposited $\mathrm{WSe}_{2}$ films are amorphous in nature. Fig. 1(b) and 1(c) show the XRD pattern of tungsten selenide films which were annealed at $300{ }^{\circ} \mathrm{C}$ and $500{ }^{\circ} \mathrm{C}$ respectively. The pattern shows well-defined peaks, suggesting that the films are polycrystalline. Tungsten selenide possesses a hexagonal structure with $a=3.29 \AA$ and $b=12.97 \AA$. The XRD pattern obtained correlated well with the standard JCPDS (06-0080) data. Peaks corresponding to (llll $\left.0 \begin{array}{ll}0 & 4\end{array}\right),\left(\begin{array}{lll}1 & 0 & 2\end{array}\right),\left(\begin{array}{lll}1 & 0 & 3\end{array}\right),\left(\begin{array}{lll}1 & 0 & 6\end{array}\right),\left(\begin{array}{lll}1 & 1 & 0\end{array}\right),\left(\begin{array}{lll}1 & 0 & 8\end{array}\right)$ were observed. The observed peaks were identified and matched with the reported values [3]. The crystallite grain size in the film was calculated using the Scherer's formula [4]:

$$
D=0.94 \lambda / \beta \cos \theta(\mathrm{nm}),
$$

where $D$ is the crystallite size, $\lambda$ is the wavelength of the $k_{\alpha}$ line, $\beta$ is the full width at half maxima (FWHM) in radians and $\theta$ is the Bragg's angle. The crystallite grain size increased from $9-11 \mathrm{~nm}$ as the annealing temperature was increased [5]. 


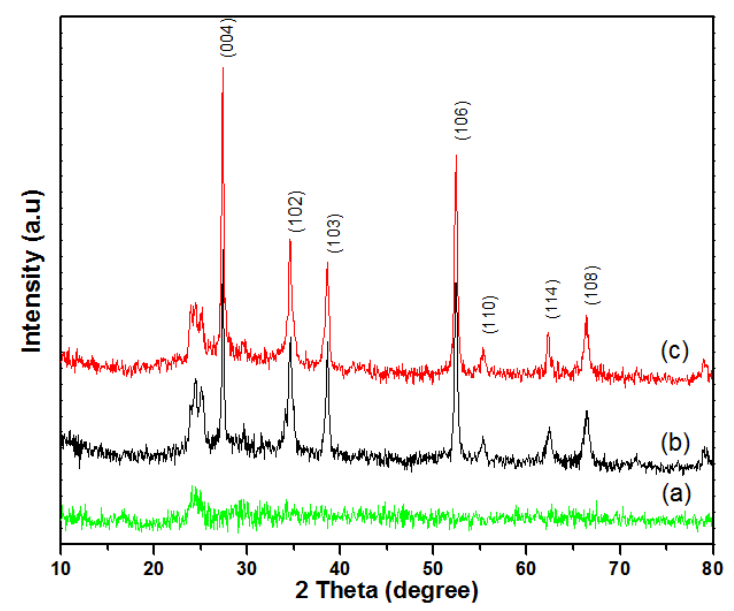

FIG. 1. WSe 2 film as deposited (a); annealed at $300{ }^{\circ} \mathrm{C}(\mathrm{b})$ and $500{ }^{\circ} \mathrm{C}$ (c)

\subsection{Morphological study of tungsten selenide thin films}

Figure 2(a-b) shows SEM images of tungsten selenide films. Detailed morphological study of the films was carried out using the JSM-6390 instrument. At $1.500 \times$ magnification the film shows a clear picture. When the magnification is increased from 1.500 to 10.000 the flakes type crystals are found. Smooth surface is obtained in the as-deposited film. The particle size was found to increase as the annealing temperature was increased [6].

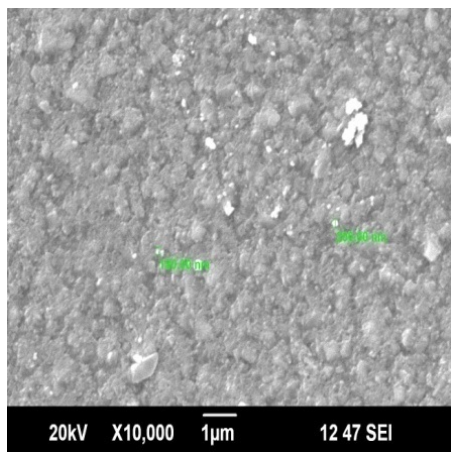

(a)

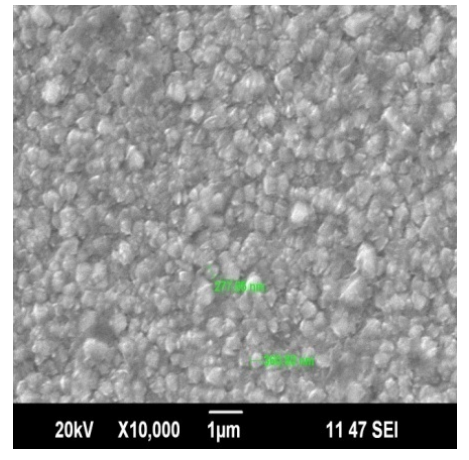

(b)

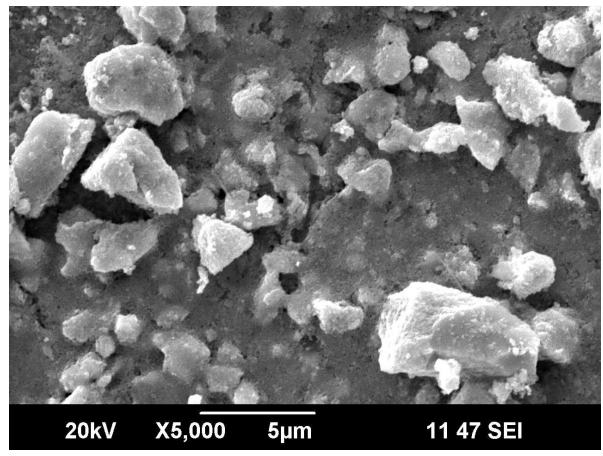

(c)

FIG. 2. As-deposited tungsten Selenide (a); film annealed at $300{ }^{\circ} \mathrm{C}$ (b) and $500{ }^{\circ} \mathrm{C}$ (c)

\subsection{EDAX analysis of tungsten selenide films}

The EDAX spectrum was recorded in the binding energy region of $0-10 \mathrm{keV}$ Fig. 3(a,b) reveal the presence of tungsten, selenium, oxygen and other elements like silicon, tin on the FTO substrate. EDAX analysis of the elements present, mass $\%$ and atom $\%$ of tungsten selenide films are also tabulated [7] (Table 1).

TABle 1. Mass and Atom percentage of $\mathrm{WSe}_{2}$ annealed at $500{ }^{\circ} \mathrm{C}$ and $500{ }^{\circ} \mathrm{C}$

\begin{tabular}{|c|c|c|c|c|}
\hline \multirow{2}{*}{ Sample } & \multicolumn{2}{|c|}{ Mass \% } & \multicolumn{2}{c|}{ Atom \% } \\
\cline { 2 - 5 } & Tungsten & Selenium & Tungsten & Selenium \\
\hline As-deposited & 2.16 & 0.47 & 1.18 & 0.6 \\
\hline Annealed at $500{ }^{\circ} \mathrm{C}$ & 42.37 & 3.82 & 23.8 & 4.99 \\
\hline
\end{tabular}




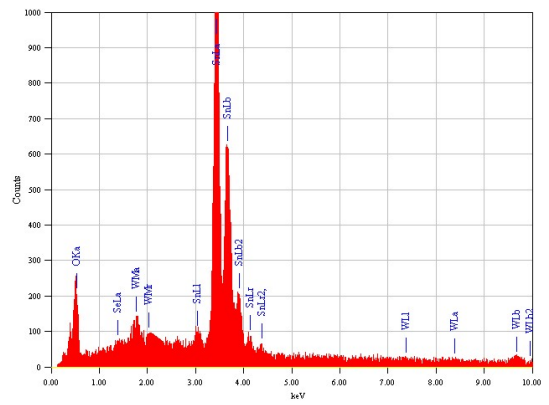

(a)

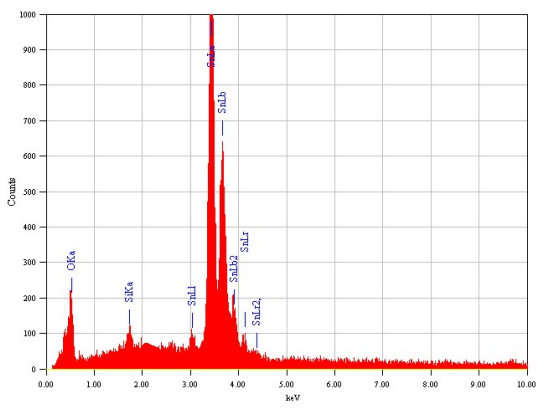

(b)

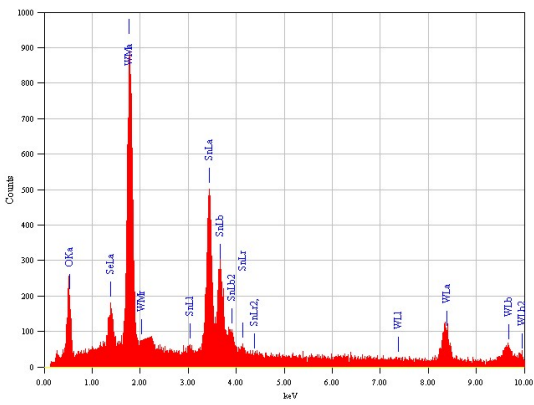

(c)

FIG. 3. $\mathrm{WSe}_{2}$ as deposited (a); annealed at $300{ }^{\circ} \mathrm{C}$ (b) and $500{ }^{\circ} \mathrm{C}$ (c)

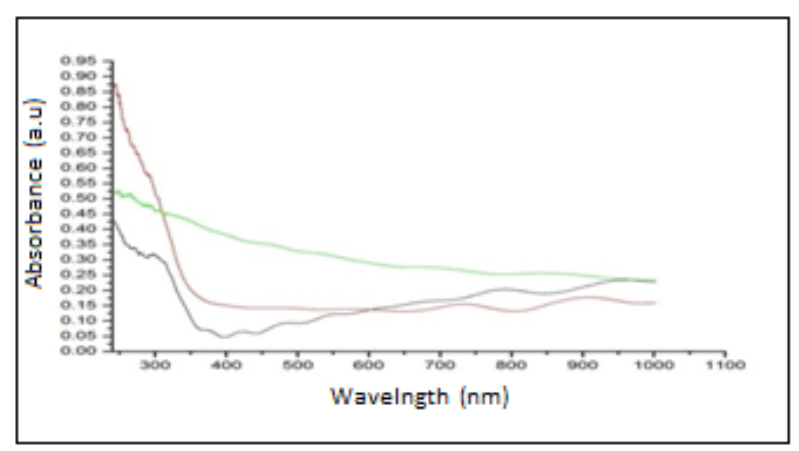

(a)

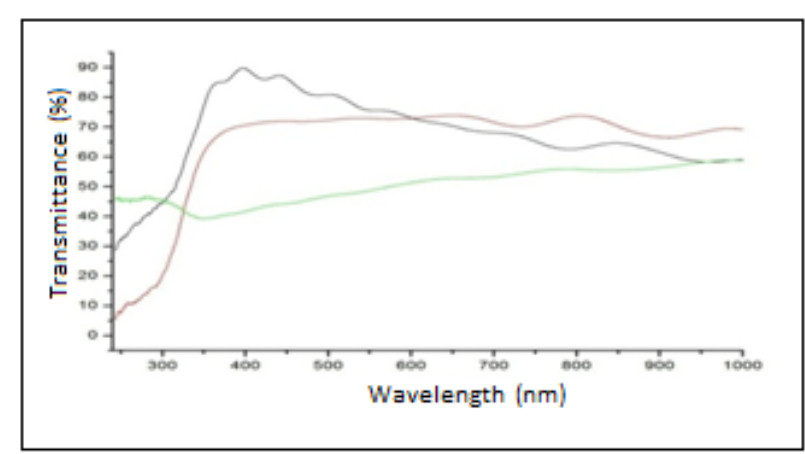

(b)

FIG. 4. Absorption (a) and transmittance (b) spectra for Tungsten Selenide films

\subsection{Optical absorption and transmittance measurement}

Typical optical absorbance and transmittance $T(\%)$ spectra of the films prepared using brush plating method are presented in Fig. 4(a,b) respectively for the as-deposited and annealed samples (at $300{ }^{\circ} \mathrm{C}$ and $500{ }^{\circ} \mathrm{C}$ ). Annealing the film at $300{ }^{\circ} \mathrm{C}$ and $500{ }^{\circ} \mathrm{C}$ did cause some changes in the optical transmittance and absorbance spectra of the films.

The typical optical absorbance and transmittance spectra of as-deposited and annealed films of tungsten selenide have been recorded and the band gap values for the films were estimated. For this, the transmittance spectra were corrected for the loss due to reflectance. The direct and indirect band gap values were obtained from plots of $\alpha_{g}^{2}, \alpha_{g}^{1 / 2}$ respectively, against the corresponding photon energy $(h \nu)$ values. Table 2 shows band gap energy of Tungsten selenide thin films for as-deposited as well as for the annealed at $300{ }^{\circ} \mathrm{C}$ and $500{ }^{\circ} \mathrm{C}$. These optical band gap values are close to that of the already reported materials used in solar cells, which means that these films reveals good optical property necessary for this purpose [8].

TABLE 2. Direct and Indirect band gap of $\mathrm{WSe}_{2}$

\begin{tabular}{|c|c|c|}
\hline Tungsten Selenide & Direct band gap (eV) & Indirect band gap (eV) \\
\hline As-deposited film & 2.75 & 2.375 \\
\hline Annealed at $300^{\circ} \mathrm{C}$ & 2.65 & 2.20 \\
\hline Annealed at $500^{\circ} \mathrm{C}$ & 2.48 & 2.16 \\
\hline
\end{tabular}

\subsection{Photoluminescence spectrum}

The photoluminescence spectra of the $\mathrm{WSe}_{2}$ thin films are shown in Fig. 5. From the spectra, the photons are excited at a wavelength of $280 \mathrm{~nm}$. As the annealing temperature increased, the intensity of the peak increased. From the spectra, the peaks observed in the emission spectrum of WSe thin films are at a wavelength of $560 \mathrm{~nm}$. 
The spectra of the as-deposited WSe films and the annealed films show an increase in the intensity as the annealing temperature is increased.

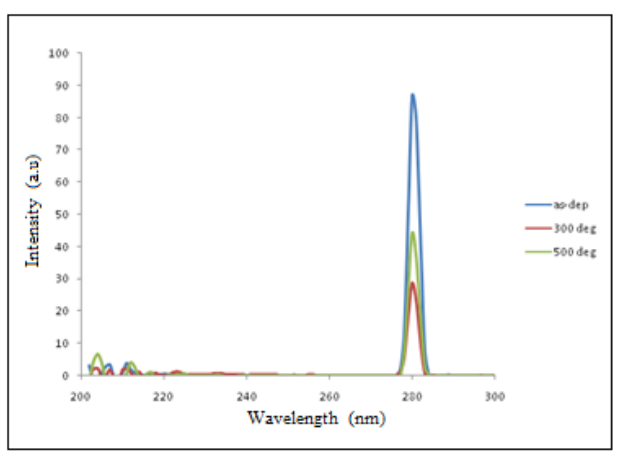

(a)

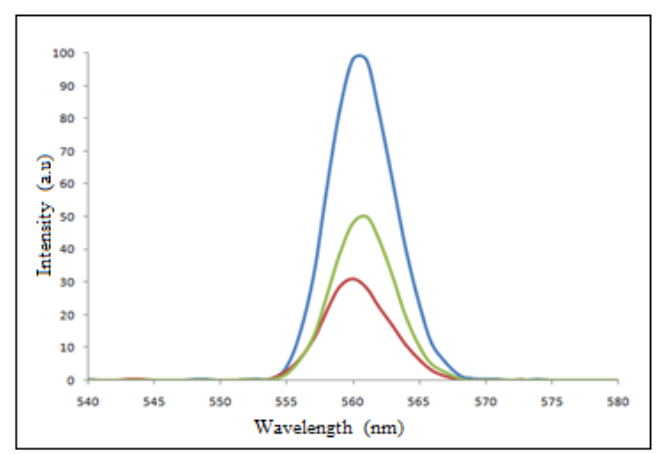

(b)

FIG. 5. Excitation (a) and emission (b) spectra of Tungsten Selenide films

\section{Conclusion}

Structural and surface morphological studies of tungsten selenide thin films deposited by a brush plating method were carried out with (i) as deposited film, (ii) film annealed at $300{ }^{\circ} \mathrm{C}$ and (iii) film annealed at $500{ }^{\circ} \mathrm{C}$. The SEM micrographs reveal changes in the surface morphology from amorphous to polycrystalline at $300{ }^{\circ} \mathrm{C}$ and an increase in the size of crystallites when annealed at $500{ }^{\circ} \mathrm{C}$. Also, the EDAX analysis confirmed the presence of tungsten and selenium in the films. Optical characterization has been performed and band gap values were obtained for the films which revealed that the films possessed very good optical properties necessary for the materials used in solar cells [9].

\section{References}

[1] Vipin kumar, Vinod Kumar, Dwivedi D.K. Growth and characterization of zinc telluride thin films for photovoltaic applications. Physica Scripta, 2012, 86, P. 015604.

[2] Liu X., Khan B.B., Tikhomirov V.K., Jha A. Semiconducting Chalcogenide Glass III: Applications of Chalcogenide Glasses. J. Non-Cryst. Solids, 1999, 294, P. 256-257.

[3] Salitra G., Hodes G., Klein E., Tenne R. Highly oriented $\mathrm{WSe}_{2}$ thin films prepared by selenization of evaporated WO 3 . Thin solid films, 1994, 245, P. 180-185.

[4] Bari R.H., Ganesan V., Potadar S., Patil L.A. Structural, optical and electrical properties of chemically deposited copper selenide films. Bull. Mater. Sci., 2009, 32, P. 37-42.

[5] Ramesh K., Thanikaikarasan S., Bharathi B. Structural, Morphological and Optical Properties of Copper Selenide Thin Films. International Journal of ChemTech Research, 2014, 6 (13), P. 5408-5411.

[6] Thi Die Thuy Ung, Quang Liem Nguyen. Synthesis and characterization of Fe doped Ti $\mathrm{O}_{2}$ photocatalyst by the Sol Gel method. Adv. Nat. Sci: Nanosci. Nanotechnol., 2011, 2, 045003.

[7] Patel P.R., Patel H.S.,et al. Growth, Structural and Electrical Characterization of Tungsten Diselenide crystal. American Journal of Condensed Matter Physics, 2013, 3 (1), P. 13-20.

[8] Arokiya Mary T. et al. A simple hydrothermal route for synthesizing copper. Selenide Nano-Flakes Elixir Nanocomposite Materials, 2012, 50, P. 10499-10500.

[9] Rajendran V., Arulmozhi Packiaseeli S., Muthumari S., Vijayalakshmi R. Temperature influence study on the copper selenide films. Nanosystems: Physics, Chemistry, Mathematics, 2016, 7 (4), P. 699-702. 